\title{
Evaluation of Pharmacology Written Question Papers of MBBS Professional Examinations
}

\author{
Brig Gen (Dr) Dipak Kumer Paul Chowdhury', Maj Gen (Dr) Debashish Saha', Professor Dr. Md. Humayun Kabir Talukder', \\ Brig Gen (Dr) Md. Ahsan Habib ${ }^{4}$, Professor (Dr) A F M Saiful Islam ${ }^{5}$, Dr. Md. Rasel Ahmad , Dr. Md. Immam Hossin
}

\begin{abstract}
This cross sectional descriptive study was conducted to observe the quality of Pharmacology professional written question papers of Bangladesh University of Professionals (BUP), University of Chittagong (CU), University of Dhaka (DU), Rajshahi University (RU) and Shahjalal University of Science \& Technology (SUST).

For this purpose total $82 \mathrm{SAQ}$ papers of five universities dated from January 2007 to July 2015 were reviewed. Question papers were reviewed to find out the coverage of recall, understanding and problem solving type questions, content coverage and presence of marking scheme in SAQ papers.

Mean percentage of recall, understanding and problem questions were $54.3 \%, 44 \%$ and $01.7 \%$ respectively in SAQ papers. Mean of the recall questions of SUST statistically significantly differed from curriculum standard $60 \%$. Other universities had no significant differences with the standard. Mean of the understanding questions of all the universities statistically significantly differed from curriculum standard $30 \%$ except BUP. There was statistically significant difference between mean of the problem solving questions of all the universities and curriculum standard $10 \%$.
\end{abstract}

Most of the SAQ papers (62\%) were without problem based questions. No question paper was found having different types question as per curriculum standard.

Total $15(18.3 \%$ ) SAQ papers contained $100 \%$ topics (all the 11 groups). Thirty nine (47.6) contained 10 groups and $22 \%$ contained 9 groups out of 11 . Twelve percent SAQ papers contained less $80 \%$ topics

Total 29 (35.4\%) SAQ papers of all the universities showed marking scheme on the questions papers, rest $64.6 \%$ were devoid of it. Maximum $87.5 \%$ SAQ papers of RU had marking scheme.

Findings of this study may be used to redefine the distribution of different types question in SAQ papers and to improve the quality of question papers by ensuring their coverage.

Key Words: Quality, SAQ, MCQ

\section{Introduction}

Assessment is the process by which teachers judge whether the learning objectives of the course are met. ${ }^{1}$ The educational objectives can be broadly allocated to three domains- knowledge, skill and attitude, i.e. what we know,

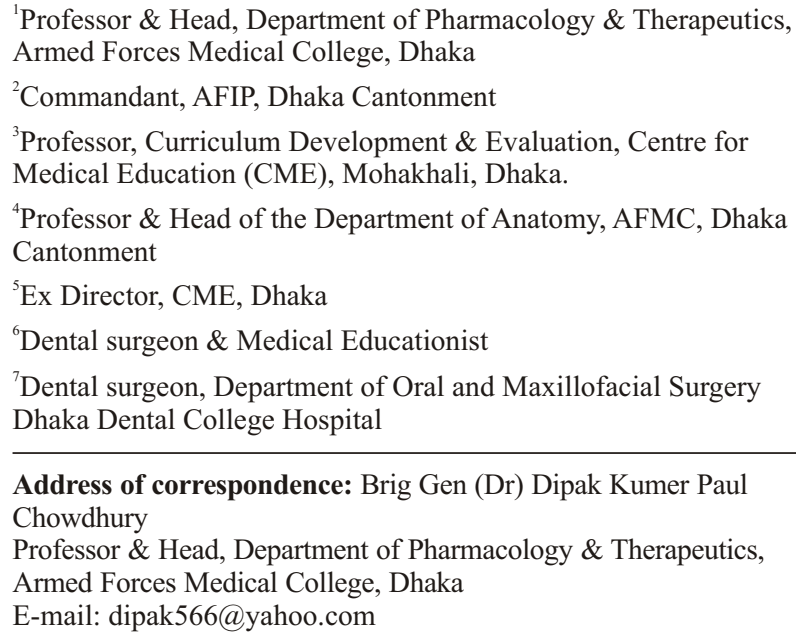

Address of correspondence: Brig Gen (Dr) Dipak Kumer Paul Chowdhury

Professor \& Head, Department of Pharmacology \& Therapeutics, Armed Forces Medical College, Dhaka

E-mail: dipak566@yahoo.com

what we do and what we feel. Knowledge includes all cognitive process from the mere recall of facts through comprehension and understanding to an ability to solve problem. Skills include the various psychomotor skills those are required to be performed by a competent physician. Attitude includes the personal qualities of students and their attitude towards medicine, their patients and their peers. ${ }^{2}$ There are different assessment instruments to judge the different learning outcomes. Curriculum for Undergraduate Medical Education in Bangladesh-2002 have introduced short answer questions (SAQ) and multiple choice questions (MCQ) for written examination, objective structured practical examination (OSPE) and objective structured clinical examination (OSCE) for practical examinations and structured oral examination (SOE) for viva examinations to assess the different domains of learning objectives of undergraduate medical students . ${ }^{3}$ No single assessment instrument is perfect and no single tool can test all aspect of medical competence and performances. Each instrument has its strengths and weakness. ${ }^{4}$ Some of the assessment tools are inherently subjective, while the rest of them may be applied with greater degree of objectivity. No method of assessment can however be intrinsically flawless. ${ }^{5}$ Open

Bangladesh Journal of Medical Education 2017;8(2):12-17. (C) 2017 Chowdhury et al., publisher and licensee Association for Medical Education. This is an Open Access article which permits unrestricted non-commercial use, provided the original work is properly cited. 
ended short answer questions (SAQ) are perhaps the most widely accepted question type for written assessment. Their format is commonly believed to be intrinsically superior to a multiple choice format though much evidence shows that this assumed superiority is limited. Short answer open ended questions should be aimed at the aspects of competence that cannot be assessed in any other way. ${ }^{6}$

Before the implementation of 2002 curriculum for undergraduate medical education in Bangladesh, written assessment of the students was carried out by essay questions. Essay questions have many disadvantages in covering content and judging students' actual learning. Furthermore essay type questions are very much subjective in nature. To overcome these disadvantages Curriculum for undergraduate medical education-2002 implemented a dramatic change in the written assessment, introducing short answer questions (SAQ) and multiple choice questions (MCQ).

Five public universities, Bangladesh University of Professionals (BUP), University of Chittagong (CU), University of Dhaka (DU), Rajshahi University (RU) and Shahjalal University of Science \& Technology (SUST) are conducting MBBS examination of all medical students except two (Gonoshasthaya SamajVittik Medical College and University of Science \& Technology Chittagong). There are some differences among the universities in the distribution of content in the different groups but all the universities suggested distribution of question type both in SAQ and MCQ would be: recall type- $60 \%$, understanding type-30\% and problem based type-10\%.?. After implementation of the curriculum 2002 pharmacology professional written examination had been conducting following this rules since January 2007. During this period, no evaluation has been done whether the pharmacology professional written question papers of different universities are fulfilling the stated requirements about content coverage and coverage of different level of cognitive domain. This study tried to find out the actual content coverage and knowledge domain coverage as per stated in the curriculum.

\section{Method}

The study was a Cross-sectional descriptive study and was conducted over one year period starting from July 2015 to June 2016 at Centre for Medical Education (CME). For collection of data the Bangladesh University of Professional (BUP), Chittagong University (CU), Dhaka University (DU), Rajshahi University (RU) and Shahjalal University of Science \& Technology (SUST) of Bangladesh were chosen as they conduct MBBS course. All the available (BUP14,CU-18,DU-18,RU-16 \& SUST-16) 2) total $822^{\text {nd }}$ professional MBBS Pharmacology SAQ papers from January 2007(starting of $2^{\text {nd }}$ professional examination under Curriculum 2002) to July 2015 of five public universities of Bangladesh were reviewed. Each SAQ paper was the sampling unit. Checklists were used to review the domain and content coverage in SAQ papers

Each SAQ paper was reviewed first for marking scheme.
Marks were given to each part of the SAQ papers which were not with marking scheme. Then question papers were highlighted by text marker of three colours to differentiate three types question-green for recall, yellow for understanding and pink for problem based questions according to the operational definition. Marks of different parts of the questions were recorded on a checklist according to type and content area. For each question paper there was separate checklist. Marks of each type and content area were summed up. Absent topic in the question paper was marked and number of topics area covered was recorded on the checklist. Marking scheme presence or absence was also recorded on the same checklist.

After data collection a quality control check was made for completeness and internal consistency. The data were then entered in the computer, process and analysis were done by using computer SPSS 19programme. Interpretations were made subsequently. Data were presented in table and graph with necessary description where necessary for easy understanding and interpretation.

Necessary permission was taken from all the concerned authorities to conduct the study. All concerned were thoroughly briefed about the study and only the volunteer respondents were included in the study. Name of the teachers will not be disclosed. Findings of the study will be used only for research purpose.

\section{Results}

A total of 82 SAQ papers (BUP-14,CU-18,DU-18,RU-16 \& SUST-16) of $2^{\text {nd }}$ professional MBBS Pharmacology written question papers dated from January 2007 to July 2015 were reviewed.

Mean of the percentage of weightage of recall questions in SAQ papers of BUP, CU, DU, RU \&SUST were 66.4, 53.0, 55.1, 52.9 and 45.4 respectively. There was statistically significant differences between BUP and other universities in case of recall questions $(p<0.001)$, between $C U$ and SUST $(p<0.05)$, between DU and $\operatorname{SUST}(\mathrm{p}<0.05)$ and between RU and SUST $(\mathrm{p}<0.05)$ (Table 1). Mean of the recall questions of SUST statistically significantly differed from curriculum standard $60 \%$. Other universities had no significant differences with the standard (Table 2). For understanding type questions these mean were 33.3, 46.8, 43.5, 45.0 and 50 for BUP, CU, DU, RU, \& SUST respectively. There was statistically significant differences between BUP and other universities in case of understanding type questions $(p<0.01)$. There were no significant differences among other universities $(\mathrm{p}>0.05)$ (Table 1).Mean of the understanding questions of all the universities statistically significantly differed from curriculum standard 30\% except BUP ( Table 2) Mean percentage of weightage of problem solving type question for the above mentioned universities were $0.3,0.2,01.4$, 02.1 and 04.6 respectively. There was statistically significant differences between SUST and BUP, CU, DU in case of problem solving type questions $(\mathrm{p}<0.01)$ (Table 1$)$.

Bangladesh Journal of Medical Education 2017;8(2):12-17. 
There was statistically significant difference between mean of the problem solving questions of all the universities and curriculum standard 10\% (Table 2) Fifty five (67.1\%) SAQ papers contained $60 \%$ or less recall questions, this is highest in SUST (93.8\%) and lowest in BUP (21.4\%). Seventy two $(87.8 \%)$ SAQ papers contained $30 \%$ or more understanding questions in case CU, DU, RU and SUST it was $100 \%$. Only $3(3.7 \%)$ SAQ papers contained $10 \%$ or more problem based questions. Most of the SAQ papers $(62.2 \%)$ had no problem solving questions (Table 3 ). In respect of recall questions $59.8 \%$ questions papers were as per curriculum standard, in case of understanding type it was only $12.2 \%$ but no question papers satisfied the standard in problem based questions (Table 4).

None of the SAQ papers of any university contained recall, understanding and problem solving questions as per curriculum standard, $14.6 \%$ SAQ papers contained recall and understanding type questions as per curriculum standard but problem based questions were less than the standard and $85.4 \%$ SAQ papers differ from standards in all respect (Table 5).

Mean percentage of the weightage of Chemotherapeutics, Cardiovascular and Renal Pharmacology, CNS Pharmacology, General Pharmacology and Autonomic Pharmacology were 17.8, 17.1, 15.6, 14.3 and 8.8 respectively (Table 6)

Total 15(18.3\%) SAQ papers contained $100 \%$ topics (all the 11 groups). Thirty nine (47.6) contained 10 groups and 22\% contained 9 groups out of 11 . Twelve percent SAQ papers contained less $80 \%$ topics (Table 7). Total 29 (35.4\%) SAQ papers of all the universities showed marking scheme on the questions papers, rest $64.6 \%$ were devoid of it. Maximum 87.5\% SAQ papers of RU had marking scheme (Table 8).

Table 1: Distribution of mean percentage of weightage of recall, understanding and problem solving type questions of different universities in SAQ papers $(\mathrm{n}=82)$

\begin{tabular}{lcccccc}
\hline Type of questions & $\begin{array}{c}\text { BUP } \\
\text { Mean } \pm \text { SD }\end{array}$ & $\begin{array}{c}\text { CU } \\
\text { Mean } \pm \text { SD }\end{array}$ & $\begin{array}{c}\text { DU } \\
\text { Mean } \pm \mathbf{S}\end{array}$ & $\begin{array}{c}\text { RU } \\
\text { Mean } \pm \mathbf{S}\end{array}$ & $\begin{array}{c}\text { SUST } \\
\text { Mean } \pm \mathbf{S}\end{array}$ & $\begin{array}{c}\text { Total } \\
\text { Mean } \pm \mathbf{S}\end{array}$ \\
\hline Recall & $66.4 \pm 6.1$ & $53.0 \pm 7.5$ & $55.1 \pm 7.2$ & $52.9 \pm 9.1$ & $45.4 \pm 7.35$ \\
\hline Understanding & $33.3 \pm 6.0$ & $46.8 \pm 7.4$ & $43.5 \pm 7.4$ & $45.0 \pm 9.2$ & $50.00 \pm 7.4$ \\
\hline Problem based & $00.3 \pm 0.72$ & $00.2 \pm 0.61$ & $01.4 \pm 2.02$ & $02.1 \pm 3.31$ & $04.6 \pm 4.31$ & $01.7 \pm 2.99$ \\
\hline
\end{tabular}

Note : Statistical Analysis between universities (ANOVA) : Recall $\mathrm{p}<0.001$; Understanding $\mathrm{p}<0.01$ and Problem based $\mathrm{p}<0.001$.

Table 2: Statistical analysis showing the degree of deviation from normal standard

\begin{tabular}{lcccc}
\hline $\begin{array}{l}\text { Statistical difference } \\
\text { from standard \% }\end{array}$ & $\begin{array}{c}\text { BUP } \\
\text { p value }\end{array}$ & $\begin{array}{c}\text { CU } \\
\text { p value }\end{array}$ & $\begin{array}{c}\text { DU } \\
\text { p value }\end{array}$ & $\begin{array}{c}\text { RU } \\
\text { v value }\end{array}$ \\
\hline Recall & 0.220 & 0.098 & 0.429 & 0.108 \\
\hline Understanding & 0.841 & 0.000 & 0.000 & 0.000 \\
\hline Problem solving & 0.000 & 0.000 & 0.000 & 0.000 \\
\hline
\end{tabular}

Table 3: Frequency distribution of SAQ papers of different universities according to coverage of different type questions $(n=82)$

\begin{tabular}{|c|c|c|c|c|c|c|c|}
\hline \multicolumn{2}{|c|}{ Type of questions } & \multirow{2}{*}{$\begin{array}{c}\begin{array}{c}\text { BUP } \\
(\mathbf{n}=\mathbf{1 4})\end{array} \\
03(21.4)\end{array}$} & \multirow{2}{*}{$\begin{array}{c}\begin{array}{c}\mathbf{C U} \\
(\mathbf{n}=\mathbf{1 8})\end{array} \\
15(83.3)\end{array}$} & \multirow{2}{*}{$\begin{array}{c}\begin{array}{c}\mathbf{D U} \\
(\mathbf{n}=\mathbf{1 8})\end{array} \\
11(61.1)\end{array}$} & \multirow{2}{*}{$\begin{array}{c}\begin{array}{c}\text { RU } \\
(n=16)\end{array} \\
11(68.8)\end{array}$} & \multirow{2}{*}{$\begin{array}{c}\begin{array}{c}\text { SUST } \\
(\mathbf{n}=\mathbf{1 6})\end{array} \\
15(93.8)\end{array}$} & \multirow{2}{*}{$\begin{array}{c}\begin{array}{c}\text { Total } \\
(\mathbf{n}=\mathbf{8 2})\end{array} \\
55(67.1)\end{array}$} \\
\hline Recall & $60 \%$ or less & & & & & & \\
\hline & More than $60 \%$ & $11(88.6)$ & $03(16.8)$ & $07(38.9)$ & $05(31.3)$ & $01(6.3)$ & $27(32.9)$ \\
\hline \multirow[t]{2}{*}{ Understanding } & $30 \%$ or more & $04(28.6)$ & $18(100)$ & $18(100)$ & $16(100)$ & $16(100)$ & $72(87.8)$ \\
\hline & Less than $30 \%$ & $10(71.4)$ & $00(00)$ & $00(00)$ & $00(00)$ & $00(00)$ & $10(12.2)$ \\
\hline \multirow[t]{3}{*}{ Problem based } & $10 \%$ or more & $00(00)$ & $00(00)$ & $00(00)$ & $01(6.3)$ & $02(12.5)$ & $03(3.7)$ \\
\hline & Less than $10 \%$ & $03(21.4)$ & $02(11.1)$ & $07(38.9)$ & $06(37.5)$ & $10(62.5)$ & $28(34 . .2)$ \\
\hline & Absent & $11(78.6)$ & $16(88.9)$ & $11(61.1)$ & $09(56.3)$ & $04(25.0)$ & $51(62.2)$ \\
\hline
\end{tabular}

Bangladesh Journal of Medical Education 2017;8(2):12-17. 
Table 4: Frequency distribution of SAQ papers of different universities according to coverage of different type questions $(\mathrm{n}=82)$

\begin{tabular}{|c|c|c|c|c|c|c|c|}
\hline \multicolumn{2}{|c|}{ Type of questions } & \multirow{2}{*}{$\begin{array}{c}\begin{array}{c}\text { BUP } \\
(n=14)\end{array} \\
10(71.4)\end{array}$} & \multirow{2}{*}{$\begin{array}{c}\begin{array}{c}\mathbf{C U} \\
(\mathbf{n}=\mathbf{1 8})\end{array} \\
12(66.7)\end{array}$} & \multirow{2}{*}{$\begin{array}{c}\begin{array}{c}\text { DU } \\
(\mathbf{n}=\mathbf{1 8})\end{array} \\
13(72.2)\end{array}$} & \multirow{2}{*}{$\begin{array}{c}\begin{array}{c}\text { RU } \\
(\mathbf{n}=\mathbf{1 6})\end{array} \\
10(62.5)\end{array}$} & \multirow{2}{*}{$\begin{array}{c}\begin{array}{c}\text { SUST } \\
(\mathbf{n}=\mathbf{1 6})\end{array} \\
4(25.0)\end{array}$} & \multirow{2}{*}{$\begin{array}{c}\begin{array}{c}\text { Total } \\
(\mathbf{n}=\mathbf{8 2})\end{array} \\
49(59.8)\end{array}$} \\
\hline Recall & $50-70 \%$ & & & & & & \\
\hline & $<50 \%>70 \%$ & $4(28.6)$ & $6(33.3)$ & $5(27.8)$ & $6(37.5)$ & $12(75.0)$ & $33(40.2)$ \\
\hline \multirow[t]{2}{*}{ Understanding } & $25 \%$ to $35 \%$ & $6(42.9)$ & $0(00)$ & $3(16.7)$ & $1(6.3)$ & $0(00)$ & $10(12.2)$ \\
\hline & $<25 \%$ to $>35 \%$ & $8(57.1)$ & $18(100)$ & $15(83.3)$ & $15(92.7)$ & $16(100)$ & $72(87.8)$ \\
\hline \multirow[t]{3}{*}{ Problem based } & $8-12 \%$ & $0(00)$ & $0(00)$ & $0(00)$ & $0(00)$ & $0(00)$ & 0 \\
\hline & $<8 \%>12 \%$ & $3(21.4)$ & $2(11.1)$ & $7(38,9)$ & $7(43.7)$ & 12() & $31(37.8)$ \\
\hline & Absent & $11(78.6)$ & $16(88.9)$ & $11(61.1)$ & $09(56.3)$ & $04(25.0)$ & $51(62.2)$ \\
\hline
\end{tabular}

Table 5: Frequency distribution of SAQ papers according the presence of different type questions as per curriculum standard $(\mathrm{n}=82)$

\begin{tabular}{|c|c|c|c|c|c|c|}
\hline Type of questions & $\begin{array}{l}\text { BUP } \\
\mathrm{f}(\%)\end{array}$ & $\begin{array}{c}\mathbf{C U} \\
\mathrm{f}(\%)\end{array}$ & $\begin{array}{c}\text { DU } \\
\mathrm{f}(\%)\end{array}$ & $\begin{array}{c}\text { RU } \\
\mathrm{f}(\%)\end{array}$ & $\begin{array}{c}\text { SUST } \\
\mathrm{f}(\%)\end{array}$ & $\begin{array}{l}\text { Total } \\
\text { f }(\%)\end{array}$ \\
\hline $\begin{array}{l}\text { Recall type: } 50-70 \% \text {, Understanding type: } 25-35 \% \text { and } \\
\text { Problem based type: } 8-12 \%\end{array}$ & $0(00)$ & $0(00)$ & $0(00)$ & $0(00)$ & $0(00)$ & $0(00)$ \\
\hline $\begin{array}{l}\text { Recall type: } 50-70 \% \text {, Understanding type: } 25-35 \% \text { and } \\
\text { Problem based type: }<8 \text { or }>12 \%\end{array}$ & $6(42.9)$ & 00 & $4(22.2)$ & $1(6.2)$ & $1(6.2)$ & $10(14.6)$ \\
\hline $\begin{array}{l}\text { Recall type: }<50 \text { or }>70 \% \text { o Understanding type: }<25 \% \text { or } \\
>35 \text { and Problem based type absent }\end{array}$ & $8(57.1)$ & $18(100)$ & $14(77.8)$ & $15(93.8)$ & $15(93.8)$ & $70(85.4)$ \\
\hline Total & $14(100)$ & $18(100)$ & $18(100)$ & $16(100)$ & $16(100)$ & $82(100)$ \\
\hline
\end{tabular}

Table 6: Distribution of marks of different topics of Pharmacology in SAQ papers of different universities ( $\mathrm{n}=82$ )

\begin{tabular}{|c|c|c|c|c|c|c|}
\hline Topics & $\begin{array}{c}\text { BUP } \\
\text { Mean } \pm \text { SD }\end{array}$ & $\begin{array}{c}\mathrm{CU} \\
\text { Mean } \pm \text { SD }\end{array}$ & $\begin{array}{c}\text { DU } \\
\text { Mean } \pm \text { SD }\end{array}$ & $\begin{array}{c}\text { RU } \\
\text { Mean } \pm \text { SD }\end{array}$ & $\begin{array}{c}\text { SUST } \\
\text { Mean } \pm \text { SD }\end{array}$ & $\begin{array}{c}\text { Total } \\
\text { Mean } \pm \text { SD }\end{array}$ \\
\hline General Pharmacology & $12.7 \pm 2.90$ & $15.0 \pm 3.22$ & $15.8 \pm 2.86$ & $13.9 \pm 2.68$ & $13.6 \pm 2.35$ & $14.3 \pm 2.96$ \\
\hline Autonomic Pharmacology & $9.6 \pm 2.52$ & $6.5 \pm 3.73$ & $9.6 \pm 2.93$ & $7.7 \pm 2.45$ & $11,0 \pm 2.29$ & $8.8 \pm 3.23$ \\
\hline Cardiovascular \& Renal Pharmacology & $14.6 \pm 3.16$ & $17.1 \pm 4.44$ & $16.5 \pm 2.98$ & $19.6 \pm 2.72$ & $17.5 \pm 2.24$ & $17.1 \pm 3.52$ \\
\hline Chemotherapeutics & $18.7 \pm 3.21$ & $17.2 \pm 2.43$ & $18.7 \pm 3.55$ & $16.5 \pm 3.76$ & $17.8 \pm 3.09$ & $17.8 \pm 3.27$ \\
\hline Endocrine Pharmacology & $8.1 \pm 3.98$ & $9.0 \pm 2.39$ & $7.2 \pm 2.98$ & $8.1 \pm 2.62$ & $7.5 \pm 2.24$ & $8.0 \pm 2.85$ \\
\hline CNS Pharmacology & $16.9 \pm 4.08$ & $16.4 \pm 4.70$ & $16.4 \pm 3.61$ & $12.6 \pm 3.13$ & $15.1 \pm 2.93$ & $15.6 \pm 3.98$ \\
\hline Respiratory Pharmacology & $3.6 \pm 1.66$ & $3.1 \pm 1.79$ & $2.1 \pm 2.14$ & $3.5 \pm 1.43$ & $3.8 \pm 1.24$ & $3.2 \pm 1.77$ \\
\hline Autacoids Pharmacology & $6.4 \pm 4.31$ & $6.0 \pm 3.80$ & $6.0 \pm 3.26$ & $9.0 \pm 3.08$ & $6.0 \pm 2.67$ & $6.7 \pm 3.57$ \\
\hline GIT Pharmacology & $4.0 \pm 2.49$ & $6.5 \pm 2.93$ & $3.3 \pm 2.54$ & $4.4 \pm 1.64$ & $3.8 \pm 1.86$ & $4.4 \pm 2.57$ \\
\hline Haemopoeitic Pharmacology & $2.4 \pm 2.13$ & $1.7 \pm 2.05$ & $1.1 \pm 1.79$ & $1.3 \pm 1.86$ & $0.7 \pm 1.46$ & $1.4 \pm 1.91$ \\
\hline Special Topics & $3.1 \pm 1.90$ & $1.5 \pm 2.10$ & $3.4 \pm 1.44$ & $3.4 \pm 1.84$ & $31 \pm 1.30$ & $2.9 \pm 1.84$ \\
\hline
\end{tabular}

Table 7: Frequency distribution of SAQ papers according to content coverage $(n=82)$

\begin{tabular}{|c|c|c|c|c|c|c|}
\hline Coverage & $\begin{array}{l}\text { BUP } \\
\mathrm{f}(\%)\end{array}$ & $\begin{array}{c}\mathbf{C U} \\
\mathrm{f}(\%)\end{array}$ & $\begin{array}{c}\text { DU } \\
\mathrm{f}(\%)\end{array}$ & $\begin{array}{c}\text { RU } \\
\mathrm{f}(\%)\end{array}$ & $\begin{array}{c}\text { SUST } \\
\mathrm{f}(\%)\end{array}$ & $\begin{array}{l}\text { Total } \\
\mathrm{f}(\%)\end{array}$ \\
\hline $100 \%$ & $6(42.8)$ & $1(5.6)$ & $2(11.1)$ & $5(31.3)$ & $1(6.3)$ & $15(18.3)$ \\
\hline$=90 \%$ to $<100$ & $4(28.6)$ & $11(61.1)$ & $5(27.8)$ & $6(37.5)$ & $13(81.3)$ & 39 (47.6) \\
\hline$=80 \%$ to $<90$ & $2(14.3)$ & $4(22.2)$ & $7(38.9)$ & $3(18.7)$ & $2(12.5)$ & $18(22.0)$ \\
\hline$<80 \%$ & $2(14.3)$ & $2(11.1)$ & $4(22.2)$ & $2(12.5)$ & $0(00)$ & $10(12.2)$ \\
\hline Total & $14(100)$ & $18(100)$ & $18(100)$ & $16(100)$ & $16(100)$ & $82(100)$ \\
\hline
\end{tabular}

Bangladesh Journal of Medical Education 2017;8(2):12-17. 
Table 8: Frequency distribution of SAQ papers according to presence of marking scheme $(n=82)$

\begin{tabular}{|c|c|c|c|c|c|c|}
\hline Marking scheme & $\begin{array}{l}\text { BUP } \\
\mathrm{f}(\%)\end{array}$ & $\begin{array}{c}\mathbf{C U} \\
\mathrm{f}(\%)\end{array}$ & $\begin{array}{c}\text { DU } \\
\mathrm{f}(\%)\end{array}$ & $\begin{array}{c}\text { RU } \\
\mathrm{f}(\%)\end{array}$ & $\begin{array}{c}\text { SUST } \\
\mathrm{f}(\%)\end{array}$ & $\begin{array}{l}\text { Total } \\
\mathrm{f}(\%)\end{array}$ \\
\hline Present & $09(64.3)$ & $03(16.7)$ & $01(5.6)$ & $14(87.5)$ & $02(12.5)$ & $29(35.4)$ \\
\hline Absent & $05(35.7)$ & $15(83.3)$ & $17(94.4)$ & $2(12.5)$ & $14(87.5)$ & $53(64.6)$ \\
\hline Total & $14(100)$ & $18(100)$ & $18(100)$ & $16(100)$ & $16(100)$ & $82(100)$ \\
\hline
\end{tabular}

\section{Discussion}

This cross sectional descriptive study was carried out by reviewing professional written question papers on Pharmacology in five public universities of Bangladesh. Total 82 SAQ papers dated from January 2007 to July 2015 of five public universities (BUP-14, CU-18, DU-18, RU-16 and SUST-16) were evaluated to observe the quality of the question papers in respect of content coverage, coverage of recall questions, coverage of understanding questions and coverage of problem based questions.

In case of content coverage, 54(66\%) question papers contained more than $90 \%$ topic area, out of these $12 \%$ contained $100 \%$ topic groups as per curriculum. Content coverage more than $90 \%$ in the question papers of SUST \& BUP were $88 \%$ and $71 \%$ respectively. In case of coverage of topic, most covered topics were chemotherapeutics $17.8 \%$, cardiovascular and renal pharmacology $17.1 \%$, CNS pharmacology $15.6 \%$, general Pharmacology $14.3 \%$ and autonomic pharmacology $8.8 \%$ respectively. There were no statistically significant differences between the universities in case of chemotherapeutics, autacoids, endocrine pharmacology and haemopoetics (ANOVA $p>0.05$ ), but there were statistically significant differences in case of other seven topics between the universities $(p<0.05)$. This differences were also found in the findings of Sindhu et al. ${ }^{8}$ Findings of this study, regarding topic coverage greatly differs from Karim \& Haque $^{9}$ in case of autonomic pharmacology (22\%) and special topics (essential drugs and rationale use of drugs) $(00 \%)$ but in this study it was found special topics covered $2.9 \%$. Findings of this study about topics coverage was consistent with the findings of Begum et al. ${ }^{10}$ in respect of CNS pharmacology but it differed in respect of autonomic pharmacology $(12.63 \%)$, chemotherapeutics (15.5\%) and cardiovascular \& renal Pharmacology (13.2\%). Previous studies were done with the question papers of 1988 curriculum. With the change of curriculum and examination system, there are positive shift of topic coverage, increasing coverage of chemotherapeutics, cardiovascular \& renal pharmacology and special topics (essential drugs and rationale use of drugs) and decreasing coverage of autonomic pharmacology.

In the coverage of cognitive domain, mean percentage of recall questions of BUP, CU, DU, RU \& SUST were $66.4 \pm 6.17,53.0 \pm 7.54,55.1 \pm 7.29,52.9 \pm 9.15 \& 45.4 \pm 7.35$ respectively. This findings are less than the findings of Karim \& Haque ${ }^{9}$ and Manara et al. ${ }^{11}$ and more than the findings of Sindhu et al.7 Except BUP all the universities recall questions coverage were less than $60 \%$. But except SUST, it was not statistically significant different from curriculum standard $60 \%$. Recall question coverage of SUST was statistically significantly less than standard $(\mathrm{p}=.000)$. Mean percentage of understanding type questions were $33.3 \pm 6.05$, $46.8 \pm 7.44,43.5 \pm 7.41,45.0 \pm 9.22 \& 50.00 \pm 7.46$ for BU, CU, DU, RU \& SUST respectively. Except BUP all are statistically significantly differed from curriculum standard $(p=0.000)$. Coverage of problem based questions for all universities were significantly differed from standard $10 \%$. Mean percentage was highest in SUST, which was $04.6 \pm 4.31$. In other universities it was less than it. None of the question papers of any university covered all three parts of cognitive domain (recall, understanding and problem based) as per curriculum standard. Fifteen percent question papers covered recall and understanding as per standard but problem based coverage was less. Problem based question was absent in most of the question papers (62\%). There was tendency to cover understanding type more and recall less than the standard in all of the universities except BUP and it was more significant in SUST, where $75 \%$ questions paper contained less than $50 \%$ recall questions and $100 \%$ question paper contain more than $35 \%$ understanding type questions.

SAQ papers were evaluated to find out whether they contain marking scheme or not. Out of 82 question papers 29 (35\%) were with marking scheme, $65 \%$ were without marking scheme. Most of the question papers 14 (87.5\%) of RU were with marking scheme, in case of BUP it was $64 \%$, CU- $17 \%$, SUST- $13 \%$ and in DU it was only $6 \%$.

\section{Conclusion}

Overall content coverage in the SAQ papers of the universities professional examination was satisfactory. But in case of coverage of different type of questions was not as per curriculum standard. Coverage of problem solving type question was negligible. Measures must be taken during moderation of university professional question papers to cover stated standard of different type questions in the curriculum.

\section{References}

1. Amin, Z \& Eng, KH 2007. Basics in Medical Education. Singapore: World Scientific Publishing Company Private Ltd., 251-265 \& 283-297.

2. Harden, RM 1979. 'Constructing multiple choice questions of the multiple true/false Type. Medical Education, July, 13(4), 305-312. 
3. BM\&DC (Bangladesh Medical and Dental Council) 2002,Curriculum for Undergraduate Medical Education in Bangladesh 2002.DGHS, Dhaka.

4. Swanwick, T 2010. Understanding Medical Education: Evidence, Theory and Practice. London Deanery: Wiley Blackwell Publication. 195-270.

5. Tarrant, M \& Ware J 2008.'Impact of item-writing flaws in multiple-choice questions on student achievement in high-stakes nursing assessments'. Medical Education, $42(2), 198-206$.

6. Schuwirth, LWT \& van der Vleuten, CPM 2013. 'Written assessment' in JA Dent \& RM Harden (eds). A Practical for Medical Teachers. Churchill Livingstone, Elsevier Limited 299-306.

7. Rules \& Procedure 2006. 'Rules\& Procedures for the conduction of $2^{\text {nd }}$ Professional MBBS Examination in Pharmacology under new curriculum'. University of Dhaka.
8. Sindhu, S, Singh, HK, Saiman, MT \& Verma, VK 2011. 'Comparative Evaluation of Pharmacology Question Papers in Medical Colleges Affiliated to Different Universities in North India along with Recommendation'. Journal of research in Medical Education \& Ethics, 1(3),180 -186.

9. Karim, A \& Haque, M 1996. 'Assessment system in Pharmacology- Does it Reflect Educational objectives and Community Health Needs'? Bangladesh J Physiol Pharmacol,12(2): 65-67.

10. Begum,M, Rahman, MS, Islam, AFMS, Khan, IA \& Akhter, N 1999. 'Eleven Years of the Undergraduate Medical Curriculum 1988: review on the changes in Pharmacology written questions'. Bangladeh $j$ PhysiolPharmacol, 15(1), 27-30.

11. Manara, A, Uddin, MN, Habib MA \& Ayub, M 2012. 'Reflection of SAQ in Undergraduate Anatomy MBBS Course according to New Curriculum of BMDC'. JAFMC Bangladesh, 8(2): 3-7. 